
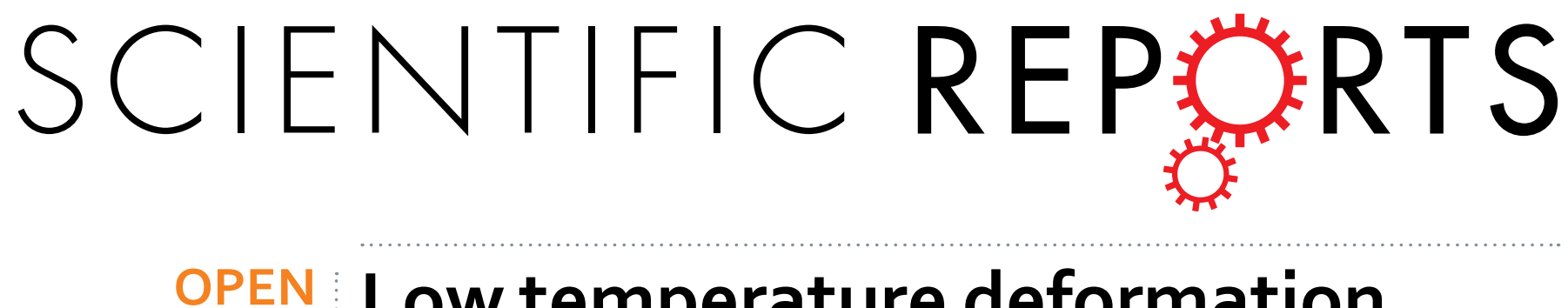

\title{
Low temperature deformation behavior of an electromagnetically bulged 5052 aluminum alloy
}

Received: 30 March 2016

Accepted: 28 June 2016

Published: 18 July 2016

\section{Zu Li, Ning Li, Duzhen Wang, Di Ouyang \& Lin Liu}

The fundamental understanding of the deformation behavior of electromagnetically formed metallic components under extreme conditions is important. Here, the effect of low temperature on the deformation behavior of an electromagnetically-bulged 5052 aluminum alloy was investigated through uniaxial tension. We found that the Portevin-Le Chatelier Effect, designated by the serrated characteristic in stress-strain curves, continuously decays until completely disappears with decreasing temperature. The physical origin of the phenomenon is rationalized on the basis of the theoretical analysis and the Monte Carlo simulation, which reveal an increasing resistance to dislocation motion imposed by lowering temperature. The dislocations are captured completely by solute atoms at $-50^{\circ} \mathrm{C}$, which results in the extinction of Portevin-Le Chatelier. The detailed mechanism responsible for this process is further examined through Monte Carlo simulation.

Fascinating attention was paid to the light weight design in the past decades due to the challenge in environmental sustainability, energy crisis and climate change. The substitution of conventional structural metals such as steel and cast iron by lightweight magnesium and aluminum alloys thus becomes crucial in lightweight manufacturing. However, aluminum alloys have inherent poor formability in contrast to conventional mild steels, especially by traditional cold forming process. This has seriously limited the extensive application of aluminum alloys in modern industries. Electromagnetic forming $(\mathrm{EMF})^{1}$ is a revolutionized manufacturing technique based on high velocity forming, which brings a plethora of advantages such as improved formability ${ }^{2-4}$, contactless forming ${ }^{5}$, reduced springback ${ }^{6,7}$, suppressed wrinkling ${ }^{8}$ and high repeatability ${ }^{5}$. These characteristics altogether enable EMF to rival most conventional mechanical processing techniques of aluminum alloys.

In the EMF of aluminum alloys, microstructural evolution has become one of major concerns due to its dominant role in determining the formed component's properties. Comparing with the alloy underwent quasi-static deformation, Risch et al. ${ }^{9}$ reported that the AA5182-type aluminum alloy after EMF exhibits small grain size and abundant dislocation motion, owing to the high strain rate deformation. Liu et al. ${ }^{10}$ also found that the high-velocity electromagnetic deformation facilitate cross-slip of dislocations, high dislocation density, and uniform dislocation configuration in 5052 aluminum alloy, which significantly promotes the plastic strain and strength. Li et al. ${ }^{11}$ revealed a textural evolution from Rotated Cube towards Cube and Goss \& Rotated Goss under EMF, accompanied with the increased dislocation density and intra-granular misorientations. In addition to the effect of high strain rate, plastic strain has been correlated to the microstructural evolution. For instance, Bach et al. ${ }^{12}$ revealed that with increasing plastic strain, dislocation density in pure aluminum increases, followed by formation of highly localized tangles into cell-like structures with different cell wall thicknesses until sub-grains finally evolve. Jiang et al. ${ }^{13}$ observed similar phenomenon in an electromagnetically bulged pure copper.

In our recent research ${ }^{14}$, we systematically investigated microstructure, texture and mechanical properties of annealed 5052 aluminum alloy tubes after EMF. The interesting finding is that the EMF induces a significant increase in yield strength and fracture strength but decrease in fractural elongation due to the strain hardening effect resulting from the increase in dislocation density and the formation of high density dislocation bands. We also probed the fatigue behavior of the electromagnetically bulged 5052 aluminum alloy through tensile-tensile fatigue testing. We found that the electromagnetically bulged specimen exhibits enhanced fatigue strength as depicted by the S-N (maximum stress $v s$. the number of cycles until failure) curves, as compared to the original (un-deformed) aluminum alloy ${ }^{15}$. Furthermore, these electromagnetically-formed aluminum alloy components

School of Materials Science and Engineering and State Key Laboratory of Material Processing and Die \& Mould Technology, Huazhong University of Science and Technology, 430074 Wuhan, PRC. Correspondence and requests for materials should be addressed to N.L. (email: hslining@mail.hust.edu.cn) 

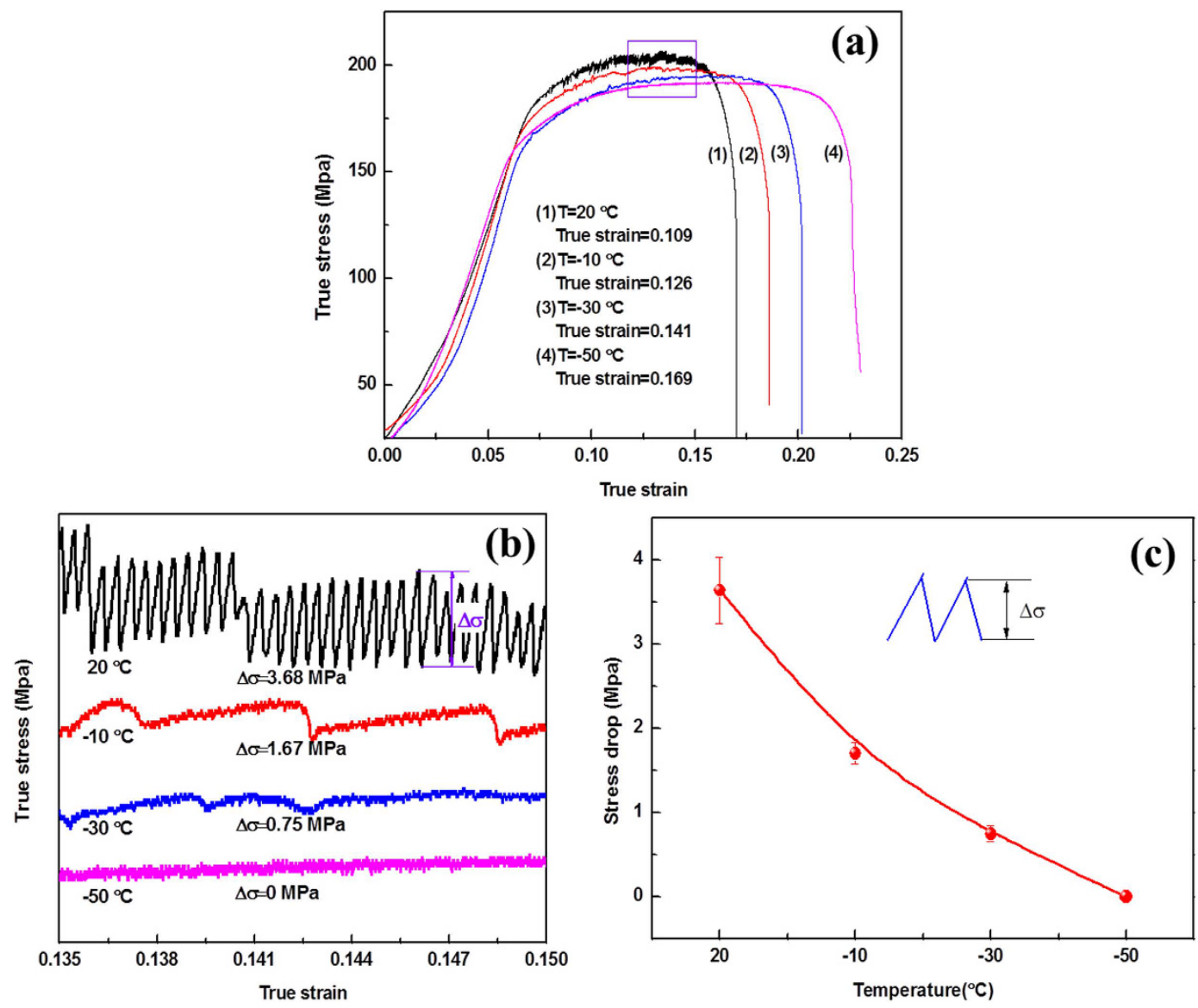

Figure 1. (a) True stress-strain curves for the EMF-bulged 5052 aluminum alloys deformed at various temperatures; (b) magnification of the square signed in (a); (c) the corresponding statistical results of stress drop with temperatures.

are usually applied in aircraft which is typically exposed in extreme conditions such as low temperatures (e.g., 50 degrees below zero). Therefore, the low temperature deformation behavior and the related mechanism of these electromagnetically-formed aluminum alloy components are of tremendous interest, whereas the research has rarely been reported thus far. In the present work, the 5052 aluminum tubes are electromagnetically bulged and the effect of low temperature on the deformation behavior of the bulged aluminum alloy is investigated through uniaxial tension. We found that the Portevin-Le Chatelier (PLC) Effect known as serrated features in stress-strain curves continuously decays until completely disappears with decreasing temperature. This phenomenon can be understood in-depth on basis of the interaction of solute atoms and dislocations under various temperatures. Our findings deliver a fundamental understanding to the low temperature deformation behavior of electromagnetically bulged aluminum alloys.

\section{Results}

Temperature dependent Portevin-Le Chatelier Effect. Figure 1a illustrates true stress-strain curves of the electromagnetically bulged 5052 aluminum alloy under low temperature (ranging from $20^{\circ} \mathrm{C}$ to $-50^{\circ} \mathrm{C}$ ) tension with a stain rate of $1 \times 10^{-3} \mathrm{~s}^{-1}$. On the whole, the plastic strain increases with the reduction of temperature, for example, at ambient temperature, the true strain $(\varepsilon)$ is about 0.109 , while $\varepsilon$ increases up to 0.126 and 0.141 when temperature decreases to $-10^{\circ} \mathrm{C}$ and $-30^{\circ} \mathrm{C}$, respectively. This tendency becomes more conspicuous for the specimen tested at $-50^{\circ} \mathrm{C}$, wherein the true strain advances to about 0.169 . The similar phenomenon can also be observed in strength $(\sigma)$ of the electromagnetically bulged 5052 aluminum alloy, $\sigma$ decreases with reducing temperatures, exhibits a softening effect. From Fig. 1a, we also notice that most curves exhibit continuous serrated flow characterization in a certain range of plastic strains, these serrated flow features are well known as the Portevin-Le Chatelier (PLC) Effect ${ }^{16-19}$.

In order to further investigate the effect of temperature on the deformation behavior of the electromagnetically bulged 5052 aluminum alloy, the stress-strain curves at a certain range of strains (from 0.135 to 0.150 located in a relative stable state) are magnified, as depicted in Fig. 1b. To clearly distinguish each stress-stain curve while presenting all of them in the same plot, some of the curves were shifted along the stress axis. It is worth noting that the magnitude of serrations decays with reduction of temperature from $20^{\circ} \mathrm{C}$ to $-30^{\circ} \mathrm{C}$, and finally disappears at $-50^{\circ} \mathrm{C}$. To distinguish quantifiably the difference of PLC effect caused by the variation of experimental temperatures, stress drop ( $\Delta \sigma$, the difference between the maximum stress and minimum stress in each serration, as 

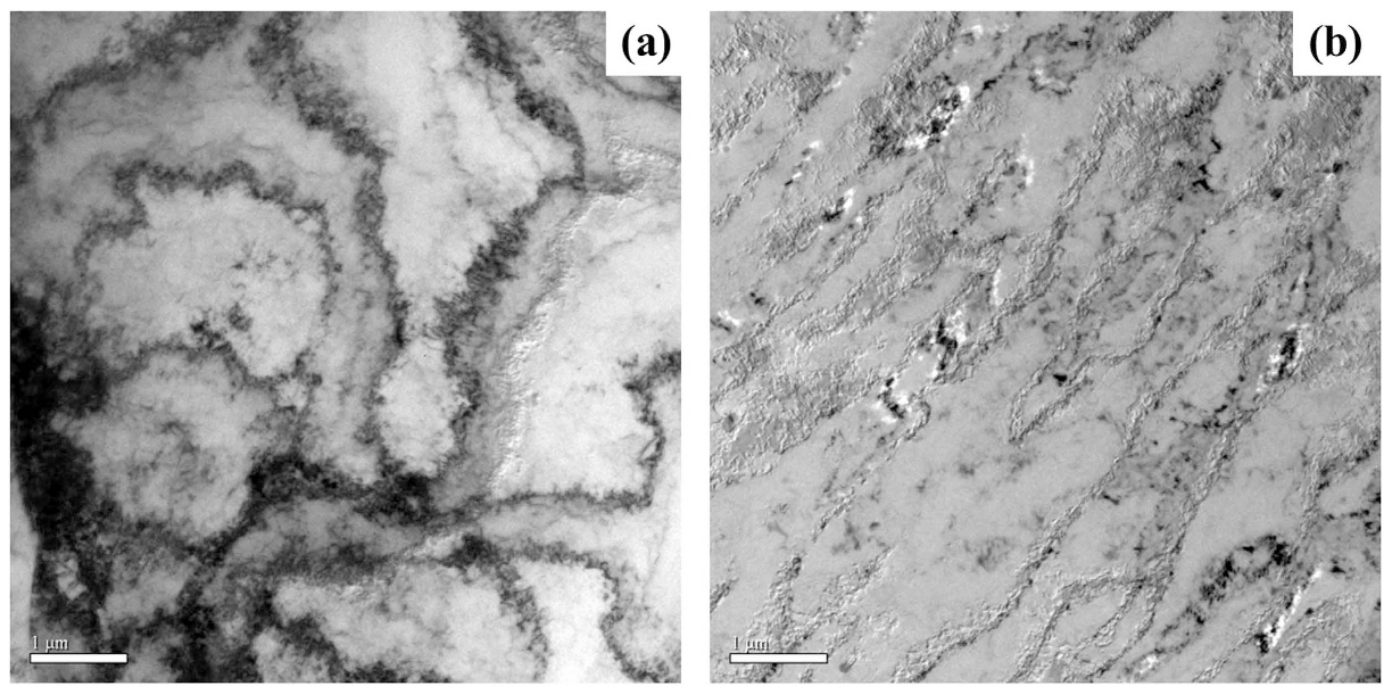

Figure 2. Dislocation structures of EMF-bulged 5052 aluminum alloys deformed at $20^{\circ} \mathrm{C}(\mathbf{a})$ and $-50^{\circ} \mathrm{C}(\mathbf{b})$.

\begin{tabular}{|l|c|c|c|c|}
\hline $\mathrm{T}\left({ }^{\circ} \mathrm{C}\right)$ & -50 & -30 & -10 & 20 \\
\hline $\mathrm{D}_{\mathrm{Mg} / \mathrm{Al}}\left(\mathrm{m}^{2} / \mathrm{s}\right)$ & $8.81 \times 10^{-31}$ & $1.42 \times 10^{-28}$ & $1.07 \times 10^{-26}$ & $2.29 \times 10^{-24}$ \\
\hline
\end{tabular}

Table 1. Diffusion coefficient of $\mathrm{Mg}$ in $\mathrm{Al}\left(\mathrm{D}_{\mathrm{Mg} / \mathrm{Al}}\right)$ at different temperature.

described in Fig. 1b) was analyzed statistically, and the statistical result of stress drop with temperatures is shown in Fig. 1c. The stress drop is about $3.68 \mathrm{MPa}$ at ambient temperature $\left(20^{\circ} \mathrm{C}\right)$, whereas it decreases linearly to about 1.67 $\mathrm{MPa}$ and $0.75 \mathrm{MPa}$ when the temperature reduces to $-10^{\circ} \mathrm{C}$ and $-30^{\circ} \mathrm{C}$, respectively, Finally, $\Delta \sigma$ equates to zero at $-50^{\circ} \mathrm{C}$, indicates temperature dependent PLC effect.

Temperature dependent deformation mechanism. To probe possible effect of low temperature on deformation mechanism, electromagnetically-bulged 5052 aluminum alloy after low-temperature tension were characterized by transmission electron microscope (TEM), and the results are presented in Fig. 2 . Here the bright field images of specimens tested under $20^{\circ} \mathrm{C}$ and $-50^{\circ} \mathrm{C}$ are selected for further analysis. From Fig. 2a, dislocation configuration is characterized by irregular dislocation cells mixed with loose dislocation tangles, indicates that the cross slipping dominates dislocation motion in the electromagnetically formed aluminum alloy at ambient temperature. However, when the experimental temperature decreases to $-50^{\circ} \mathrm{C}$, parallel dislocation bands can be clearly observed (see Fig. 2b), indicates planar slipping of dislocation ${ }^{20}$.

\section{Discussion}

In general, the serrated characteristics in stress-strain curve indicate the occurrence of heterogeneous deformation. In this case, plastic stains are localized in very small regions such as shear bands or Portevin-Le Chatelier (PLC) bands, which finally causes the catastrophic fracture of the sample ${ }^{20}$. Therefore, it can be well understood that the decay of serrations with decreasing temperature from $20^{\circ} \mathrm{C}$ to $-50^{\circ} \mathrm{C}$ corresponds to the increase of plastic strains, as depicted in Fig. 1a.

This temperature dependent PLC effect can be understood fundamentally on the basis of the interaction between solute atoms and dislocations. Dislocation usually operates at yield stress wherein the lattice elastic distortion generates stress field $(\mathrm{P})$ around dislocations ${ }^{21,22}$, causing enthalpy change $P \Delta V(\Delta V$ is solute misfit volume). In this case, solute atoms diffuse to dislocations in order to release stress and minimize system energy $\mathrm{y}^{17,21,23}$. These solute atoms around dislocations are usually called "Cottrell atmosphere" 24 that usually pins dislocations, which causes an increase of frictional stress ${ }^{25}$ around solute atoms, and impedes dislocation motions. Therefore, high external stress is required to overcome this pinning energy, results in an increase of stress. Once external stress subjugates pinning energy, dislocations extricate the constraint of solute atoms, causing an instantaneous stress drop. The continuous process of pinning-shake off, leading to the serrated characteristics in stress-strain curves, known as the Portevin-Le Chatelier (PLC) effect $^{17,26,27}$ as observed in Fig. 1 . The above interactions between solute atoms and dislocations, affected inherently by temperature, which can be understood in-depth according to the diffusion rate $(D)$ of solute atoms based on the Arrhenius equation ${ }^{28}$ :

$$
D=D_{0} \exp \left(-\frac{Q}{R T}\right)
$$

in which $D_{0}=6.23 \times 10^{-4} \mathrm{~m}^{2} / \mathrm{s}$ is the diffusion constant, $Q=1.19 \mathrm{eV}$ is the diffusion activation energy, $R=$ $8.314 \mathrm{~J} /(\mathrm{mol} \cdot \mathrm{K})$ is the gas constant ${ }^{28}$ and $T$ is the absolute temperature. From equation (1), temperature is the decisive parameter for diffusion rate of solute atoms. Therefore, diffusion rates at various temperatures can be 


\begin{tabular}{|l|c|c|c|c|c|c|}
\hline $\mathbf{M g}$ & $\mathbf{S i}$ & $\mathbf{F e}$ & $\mathbf{C u}$ & $\mathbf{M n}$ & $\mathbf{T i}$ & $\mathbf{A l}$ \\
\hline $2.0-2.8$ & 0.4 & 0.4 & 0.1 & $0.15-0.4$ & $<0.1$ & Balance \\
\hline
\end{tabular}

Table 2. Nominal composition of the 5052 aluminum alloy (in wt.\%).
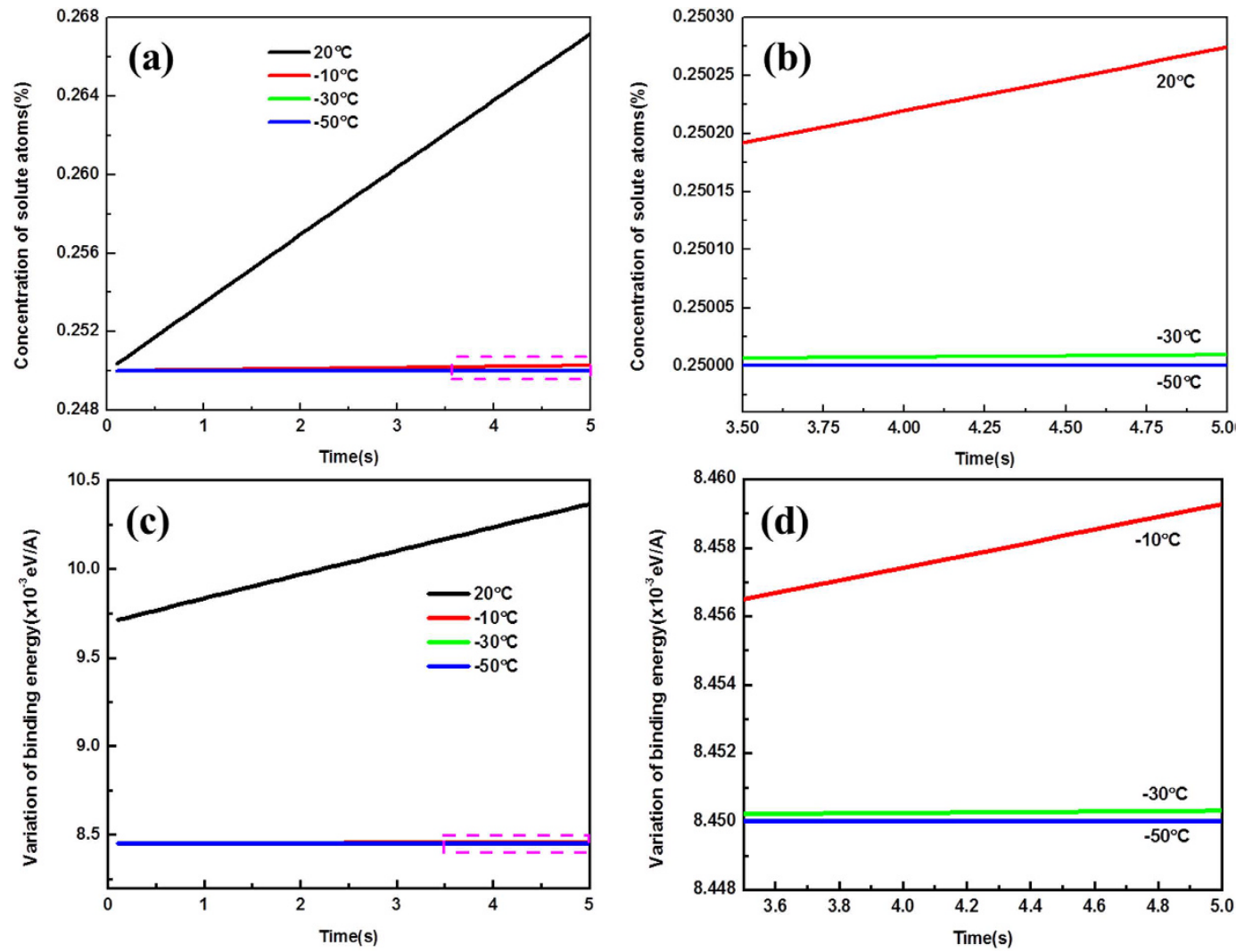

Figure 3. (a,b) The calculated concentration of solute atoms around the dislocation; (c,d) variation of binding energy between solute atoms and dislocation per unit length.

calculated and results are listed in Table 1, from which $D$ is $2.29 \times 10^{-24} \mathrm{~m}^{2} / \mathrm{s}$ under room temperature uniaxial tension, but it decreases monotonously from $1.07 \times 10^{-26} \mathrm{~m}^{2} / \mathrm{s}$ to $1.42 \times 10^{-28} \mathrm{~m}^{2} / \mathrm{s}$ with reducing temperature from $-10^{\circ} \mathrm{C}$ to $-30^{\circ} \mathrm{C}$. This tendency becomes conspicuous at $-50^{\circ} \mathrm{C}\left(D=8.81 \times 10^{-31} \mathrm{~m}^{2} / \mathrm{s}\right)$, indicates serious difficulties of solute atoms diffuse at low temperature.

According to "cross-core diffusion" model, the concentration of solute atoms $(c(t))$ around the dislocation can be expressed as ${ }^{23}$

$$
c(t)=c_{0}+\Delta c(t)=c_{0}+c_{0} \tanh (\beta \overline{\Delta W} / 2)\left[1-e^{-6 \cosh (\beta \overline{\Delta W} / 2) \Gamma_{c} t}\right]
$$

in which $C_{0}=2.5 \%$ is the bulk solute concentration ${ }^{20}, \Delta W=0.13 \mathrm{eV}$ is the average binding energy difference, $\beta=1 / k T\left(k=1.38 \times 10^{-23} \mathrm{~J} / \mathrm{K}\right.$ is the Boltzmann constant and $T$ is the absolute temperature $), \Gamma_{c}=v_{0} e^{-\beta \Delta H_{c}}$ is the transition rate $^{23}\left(v_{0}=3.8 \times 10^{13} \mathrm{~s}^{-128}\right.$ is the attempt frequency and $\Delta H_{c}=0.97 \mathrm{eV}^{23}$ is the average activation enthalpy). By applying the data listed in Table 2, the concentration of solute atoms around dislocations can be calculated and plotted in Fig. 3a. It is shown that $c(t)$ around dislocations decreases with the reduction of temperature, especially from $20^{\circ} \mathrm{C}$ to $-10^{\circ} \mathrm{C}$, and this tendency continues at low temperatures from $-10^{\circ} \mathrm{C}$ to $-50^{\circ} \mathrm{C}$, as depicted in Fig. 3b. The variation of solute atoms concentration $(\Delta c(t))$ then induces the change of binding energy $(\Delta E(t))$ between solute atoms and dislocations per unit length, here ${ }^{23}$

$$
\Delta E(t)=\Delta c(t) N \overline{\Delta W}
$$

in which $N=2 w / \sqrt{3} b^{2}$ is the number of solute atoms around the dislocation with a width $w \approx 21 \AA^{23}$ $b=0.285 \mathrm{~nm}^{29}$. According to equation (3), $\Delta \mathrm{E}(\mathrm{t})$ are calculated and the result is depicted in Fig. $3 \mathrm{c}$. Conspicuous decrease of binding energy can be detected when the temperature decreasing from $20^{\circ} \mathrm{C}$ to $-10^{\circ} \mathrm{C}$, and then this reduction becomes gradual from $-10^{\circ} \mathrm{C}$ to $-50^{\circ} \mathrm{C}$ (Fig. 3d), which responsible for the serrated characteristics in stress-strain curves as observed in Fig. $1 \mathrm{~b}$.

The micro-mechanism of the present phenomenon can be further understood through Monte Carlo simulation. Here, the simulated results at two typical temperatures (namely $20^{\circ} \mathrm{C}$ and $-50^{\circ} \mathrm{C}$ ) are selected for analysis. 

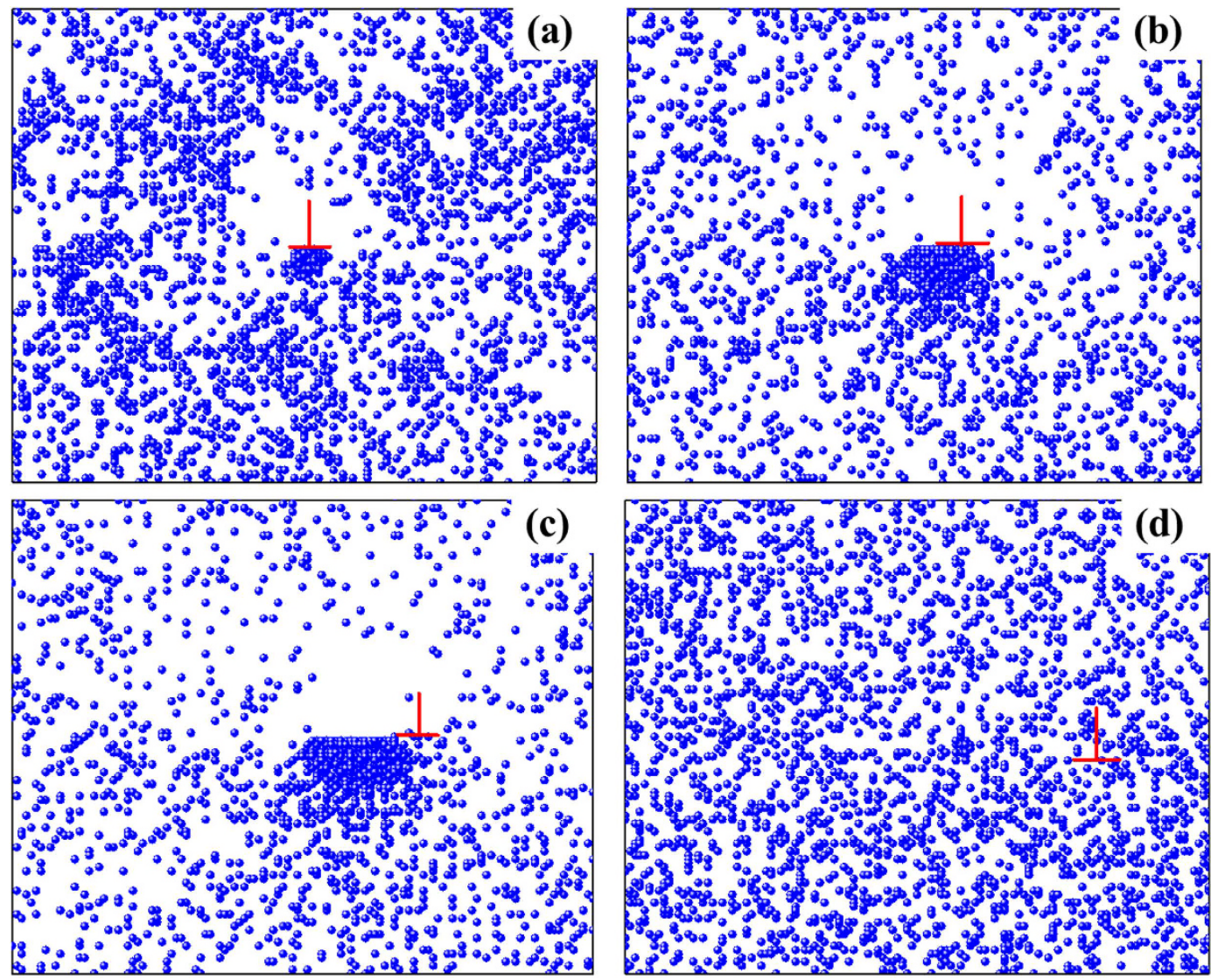

Figure 4. The simulated distribution of solute atoms around dislocation under $20^{\circ} \mathrm{C}$ at various moments: (a) $10^{6}(1 / \Gamma),(\mathbf{b}) 10^{7}(1 / \Gamma),(\mathbf{c}) 10^{8}(1 / \Gamma),(\mathbf{d}) 5 \times 10^{8}(1 / \Gamma)$.

Figure 4 shows the interactions between solute atoms and dislocations at various time when $T=20^{\circ} \mathrm{C}$. It is clear that when $t=1.0 \times 10^{6}(1 / \Gamma)$, partial solute atoms gather below the dislocation (Fig. 4a), and then, the quantity of agminated solute atoms rises synchronously with increasing time (Fig. 4b,c), which forms Cottrell air ass and increases deformation stress. Dislocations finally shake off the shackle of solute atoms (Fig. 4d) and move freely due to the effect of thermal activation ${ }^{24,30}$, results in stress dropping. The continuous process of pinning-shake off, results in PLC effect as observed in Fig. $1 b^{31,32}$.

The interaction between solute atoms and dislocations at $-50{ }^{\circ} \mathrm{C}$ is depicted in Fig. 5. Due to the decay of diffusion coefficient with dropping temperature (Table 1), the motion of dislocations becomes slow. Therefore dislocations hardly shake off the constraint of solute atoms. In this case, solute atoms and dislocation move together, as illustrated in Fig. 5d, which annihilates the PLC effect in stress-strain curve $\mathrm{e}^{31,33-35}$.

Lowering the temperature also includes a transition of slipping mode from cross slip to planar slip as depicted in Fig. 2. As discussed above, the interaction between solute atoms and dislocations varies with temperatures. As shown in Fig. 6, in general, a perfect dislocation dissociates into two Shockley partial dislocations, expressed as:

$$
\frac{1}{2}[110] \rightarrow \frac{1}{6}[121]+\frac{1}{6}[21 \overline{1}]
$$

At ambient temperatures, the concentration of solute atoms around dislocations is high, and the size of solute atmosphere (i.e. Cottrell air ass) is large enough to surround both partials, namely, two partials are full of solute atoms (Fig. 6a). In this case, partials can join together easily to form a perfect dislocation without escaping from "solute atmosphere" ${ }^{25}$, which facilitates the cross slip and forms irregular dislocation cells mixed with loose dislocation tangles as observed in Fig. 2a. While at $-50^{\circ} \mathrm{C}$, the concentration of solute atoms around the partials is low and can't embrace partials (Fig. 6b), therefore partials have to shake off "solute atmosphere" to form a perfect one, which hinders the cross slip and tends to parallel slip.

\section{Conclusions}

In summary, the effect of temperature on deformation behavior and microstructure of 5052 aluminum alloy was investigated systemically. The conclusions can be drawn from experimental results as follows:

(1) The serrated characteristics in stress-strain curves (i.e. PLC effect) decay with the reduction of temperatures, and annihilate at $-50^{\circ} \mathrm{C}$. At ambient temperature, the continuous process of pinning-shake off between 

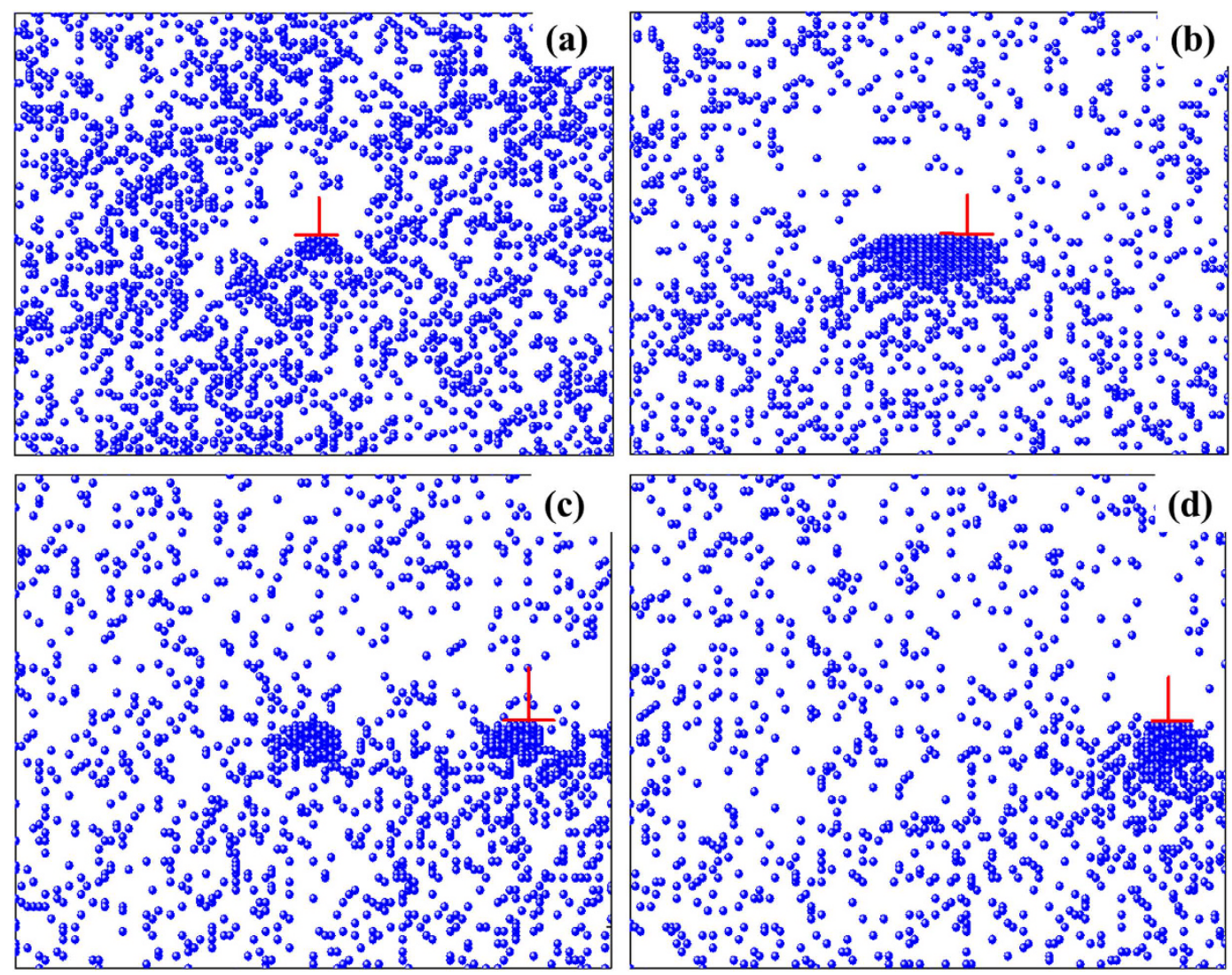

Figure 5. The simulated distribution of solute atoms around dislocation under $-50^{\circ} \mathrm{C}$ at various moments. (a) $10^{6}(1 / \Gamma),(\mathbf{b}) 10^{7}(1 / \Gamma),(\mathbf{c}) 10^{8}(1 / \Gamma),(\mathbf{d}) 5 \times 10^{8}(1 / \Gamma)$

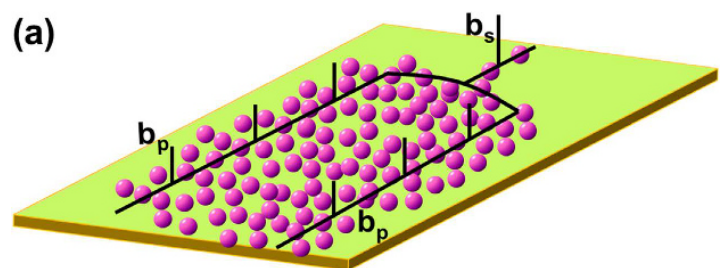

(b)

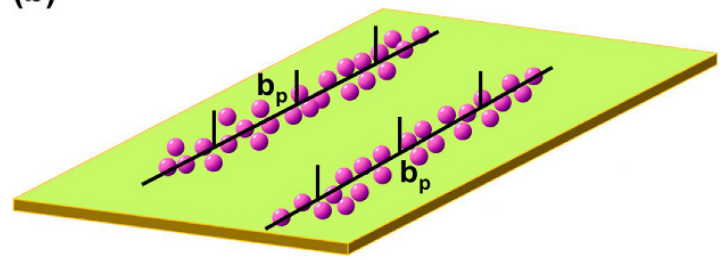

Figure 6. Dissociation of a perfect dislocation into two Shockley partial dislocations: (a) $20^{\circ} \mathrm{C}$, the size solute atmosphere is large enough to surround both partials; (b) $-50^{\circ} \mathrm{C}$, the concentration of solute atoms around the partials is low.

solute atoms and dislocations, responsible for the PLC effect. While at low temperature, the interaction between solute atoms and dislocations decays, and even move together at $-50^{\circ} \mathrm{C}$, causes the annihilation of PLC effect.

(2) The decreasing temperature also results in a transition of slipping mode from wave slip $\left(20^{\circ} \mathrm{C}\right)$ to planar slip $\left(-50^{\circ} \mathrm{C}\right)$. At ambient temperatures, the size solute atmosphere is large enough to surround both partials, and partials can join together easily to form a perfect dislocation without necessary escaping from "solute atmosphere", which facilitates the cross slip. While at low temperature of $-50^{\circ} \mathrm{C}$, the concentration of solute atoms around the partials is low, the partials have to shake off "solute atmosphere" to form a perfect one, results in parallel slipping. 


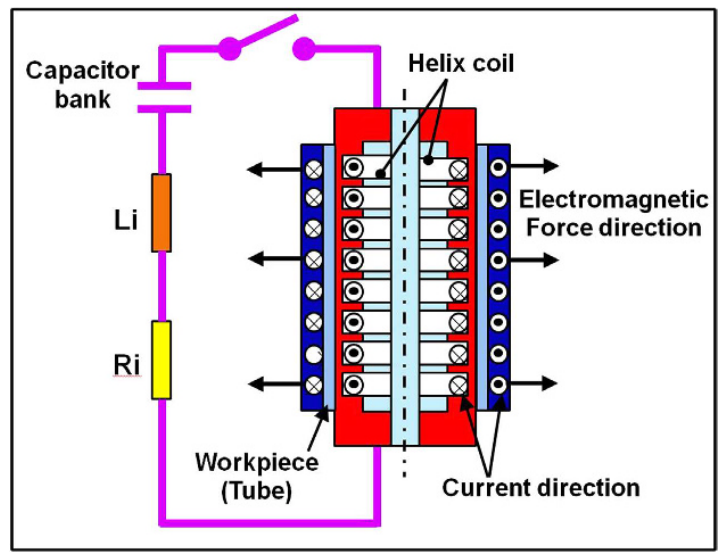

Figure 7. The scheme of the electromagnetic bulging of tube.

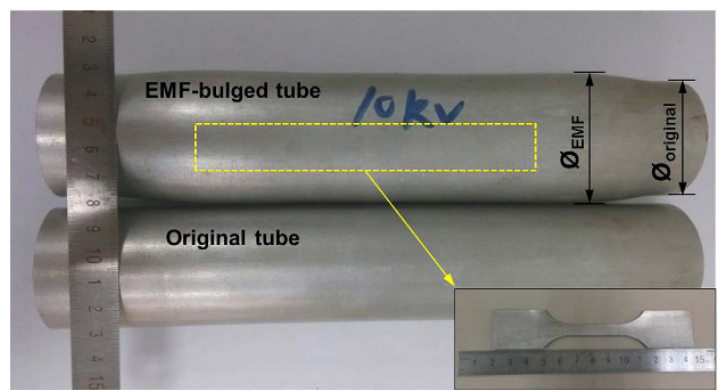

Figure 8. Photographs of the original and electromagnetically bulged tubes, the insert shows the tensile specimen cut from the yellow square of the EMF-bulged tube.

\section{Experimental Methods}

Electromagnetic bulging. The as-received 5052 aluminum alloy tube with inner diameter of $48 \mathrm{~mm}$ and thickness of $1 \mathrm{~mm}$ was supplied by Northeast Light Alloy Co., Ltd., China. The nominal chemical composition (wt. \%) of the alloy is listed in Table 2. It is notable that $\mathrm{Mg}$, Si and Fe are the solute atoms in the aluminum alloy.

The 5052 aluminum alloy specimens with length $200 \mathrm{~mm}$ used for electromagnetic bulging were fabricated by wire-cutting from the as-received tubes. In order to diminish pre-extrusion induced residual stress and dislocations in the original tube, the tube specimens were then annealed at $653 \mathrm{~K}$ for 120 minutes before electromagnetic bulging. The experiments were performed on the self-build EMF system (EMF 30) at Harbin Institute of Technology. The scheme of the experimental apparatus is depicted in Fig. 7, wherein a 22-turn helix coil with an outer-diameter of $47 \mathrm{~mm}$ and effective length of $190 \mathrm{~mm}$ was used to bulge the tubes. From Fig. 7, the system consists of a capacitor bank connected to the helix coil which was placed coaxially inside the aluminum alloy tube. The bulging of the tube was designed to be free expansion without fixtures. The coil was covered homogenously with polyimide films to provide insulation and to ensure a good coaxiality between coil and tube (the coil was wrapped uniformly with polyimide film so that the outer diameter of the coil can fit well with the tube). Upon discharging the capacitor, time-varying currents flowed through the coil and generated a transient magnetic field, which induced an eddy current in the aluminum tube and generated an opposing transient magnetic field. The interaction of these two magnetic fields created large repulsive Lorentz body forces to drive a rapid plastic deformation of aluminum alloy tubes. In the present experiments, a discharge voltage of $10 \mathrm{kV}$ was applied in the electromagnetic bulging, and at least 3 times repeated trials were carried out to ensure the reliability.

Low temperature uniaxial tensile texting and microstructure characterization. Figure 8 shows photographs of the electromagnetic bulged aluminum alloy tube as compared with the original tube. It is evident that the diameter of the electromagnetically-bulged tube becomes noticeably large after bulging $\left(\varnothing_{\text {EMF }}>\varnothing_{\text {Original }}\right.$ as shown in Fig. 8), the uniform plastic deformation indicates homogeneous distribution of microstructure. In order to probe the possible variation of mechanical properties induced by electromagnetic bulging, specimens in both original and bulged states were fabricated by wire-cutting along the longitudinal direction of the tubes (see Fig. 8), wherein the machined dog-bone shape samples with gauge length of $25 \mathrm{~mm}$ and width of $8 \mathrm{~mm}$. The uniaxial tension experiments were conducted on an electronic universal testing machine (RGM-4050) at strain rate of $1 \times 10^{-3} \mathrm{~s}^{-1}$. In order to probe the effect of low temperature on the deformation behavior of the electromagnetic-formed aluminum alloy, various experimental temperatures ranging from $20^{\circ} \mathrm{C},-10^{\circ} \mathrm{C},-30^{\circ} \mathrm{C}$ to $-50^{\circ} \mathrm{C}$ were applied. 


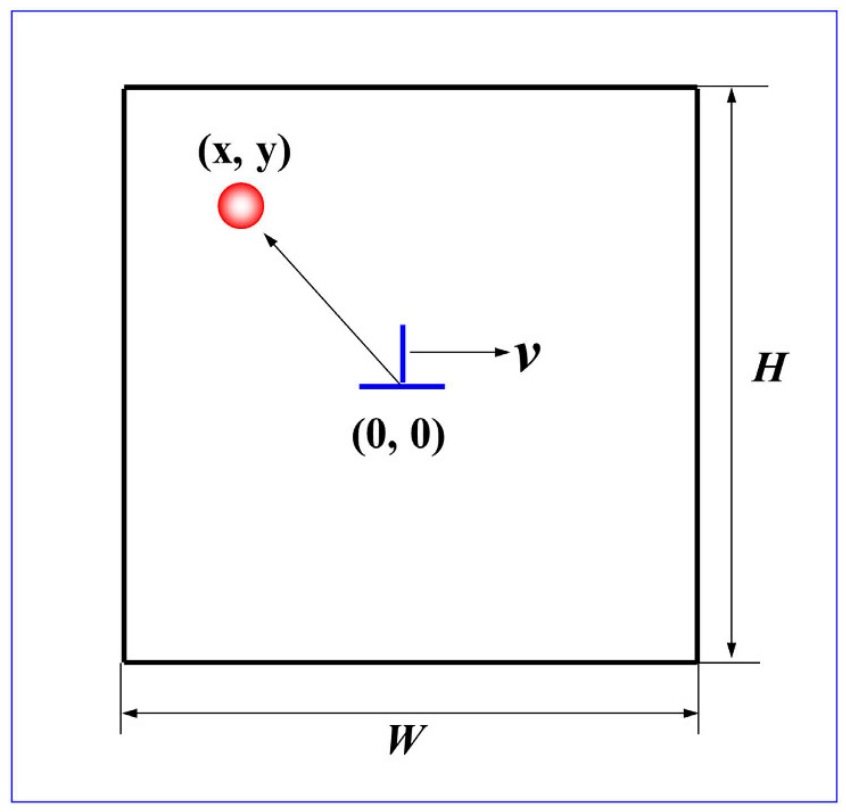

Figure 9. Schematic illustration of the simulation cell.

Microstructures of the electromagnetically-bulged aluminum alloys after uniaxial tension at various temperatures were characterized by TEM (FEIT ecnai G20). TEM thin foils were first mechanically grinded to about $50 \mu \mathrm{m}$ thick, followed by a twin-jet polishing method in a solution of $30 \%$ nitric acid and $70 \%$ methanol at a voltage of $20 \mathrm{~V}$ and at the temperature of $-20^{\circ} \mathrm{C}$.

Monte Carlo simulation. As mentioned above, there are some solute atoms (such as $\mathrm{Mg}$, $\mathrm{Si}$ and Fe shown in Table 2) in 5052 aluminum alloy, which usually causes the lattice distortion and generates stress field $(P)$ around dislocations, the enthalpy change $(\Delta E)$ can be defined as $^{36}$,

$$
\Delta E(x, y)=P \Delta V=P(V s-V a)
$$

in which $V_{s}$ and $V_{a}$ are the volumes of the solute and solvent atoms $\Delta V=6.3 \times 10^{-30} \mathrm{~m}^{330} . P$ is the pressure field associated with the position of the solute atoms that correlated to the dislocation (as depicted in the coordinates of Fig. 9), expressed as $^{29}$

$$
P=\frac{G b(1+v)}{3 \pi(1-v)} \frac{y}{x^{2}+y^{2}}
$$

where $G=27 \mathrm{GPa}$ is the isotropic shear modulus, $\nu=0.32$ is the Poisson's ratio of the 5052 aluminium alloy ${ }^{37,38}$ and $\boldsymbol{b}=0.285 \mathrm{~nm}$ is the Burgers vector of dislocation ${ }^{29}$. To better analyze dislocation movement and interaction with solute atoms, a single dislocation is introduced in present simulation ${ }^{36,37}$. The edge dislocation is restricted to glide on a single slip plane and no climb is possible, using periodic boundary conditions. The solute atom is free to move in any direction within the two-dimensional square lattice. We calculate the change in energy of the system, $\Delta E$ (equation 5), If $\Delta E<0$, the system energy decreases, the attempted move is accepted; If $\Delta E>0$, the system energy increases, accept the mobile at a certain probability ${ }^{39}$.

Monte Carlo simulation of the unit size is $200 b \times 200 b$, namely high $H=200 b$, width $W=200 b, b$ is the size of Burgers vector in 5052 aluminum alloy. The edge dislocation at the center of the unit, regarded as the origin of coordinate system, as shown in Fig. 9. Assume that each lattice point is occupied only by one solute atom (such as $\mathrm{Mg})^{38}$. The time reported in units of the minimum time required for the dislocation to advance by one Burgers vector, $1 / \Gamma^{36,40}$.

\section{References}

1. Imbert, J. \& Worswick, M. Reduction of a preformed radius in aluminum sheet using electromagnetic and conversional forming, J. Mater. Process. Technol. 212, 1963-1972 (2012).

2. Imbert, J. \& Worswick, M. Electromagnetic reduction of a pre-formed radius on AA 5754 sheet. J. Mater. Process. Tech. 211, 896-908 (2011).

3. Shang, J. H. \& Daehn, G. Electromagnetically assisted sheet metal stamping. J. Mater. Process. Tech. 211, 868-874 (2011).

4. Psyk, V. et al. Electromagnetic forming-A review. J. Mater. Process. Technol. 211, 787-829 (2011).

5. Al-Hassani, S. T. S., Duncan, J. L. \& Johnson, W. On the parameters of the magnetic forming process. J. Mech. Eng. Sci. 16, 1-9 (1974).

6. El-Azab, A., Garnich, M. \& Kapoor, A. Modeling of the electromagnetic forming of sheet metals: state-of-the-art and future needs. J. Mater. Process. Tech. 142, 744-754 (2003).

7. Li, F. Q. et al. Formability of Ti-6Al-4V titanium alloy sheet in magnetic pulse bulging. Materials \& Design. 52, 337-344 (2013). 
8. Chu, Y. Y., Lee, R. S., Psyk, V. \& Tekkaya, A. E. Determination of the flow curve at high strain rates using electromagnetic punch stretching, J. Mater. Process. Technol. 212, 1314-1323 (2012).

9. Risch, D. et al. Design and analysis of a deep drawing and in-process electromagnetic sheet metal forming process. Proceedings of the 3rd International Conference on High Speed Forming. Dortmund, Germany, doi: 10.17877/DE290R-8668, 201-212 (2008, 1).

10. Liu, D. H., Yu, H. P. \& Li, C. F. Comparative study of the microstructure of 5052 aluminum alloy sheets under quasi-static and highvelocity tension, Mater. Sci. Eng. A 551, 280-287 (2012).

11. Li, Z. G. et al. Deformation texture evolution of pure aluminum sheet under electromagnetic bulging. J. Alloy. Comp. 589, 164-173 (2014).

12. Bach, F. W., Bormann, D. \& Walden, L. Influence of Forming Rate on the Microstructure and Properties of Materials Subjected to Electromagnetic Forming. Proceedings of the 3rd International Conference on High Speed Forming. Dortmund, Germany, doi: 10.17877/DE290R-8645, 55-64 $(2008,1)$.

13. Jiang, H. W. et al. Deformation behavior and microstructure evolution of pure Cu subjected to electromagnetic bulging. Mater. Sci. Eng. A 593, 127-135 (2014).

14. Jiang, H. W. et al. Microstructure, texture and mechanical properties of $5 \mathrm{~A} 02$ aluminum alloy tubes under electromagnetic bulging. Mater. Design 82, 106-113 (2015).

15. Wang, D. Z. et al. Investigating and understanding the fatigue behavior of an aluminum alloy: influence of electromagnetic bulging. Trans. Nonfer. Met. Soc. China, accepted (2016).

16. Klose, F. B. et al. Analysis of Portevin-Le Chatelier serrations of type Bin Al-Mg. Mater. Sci. Eng. A. 369, 76-81(2004).

17. Kang, J. et al. Effect of type-B Portevin-Le Chatelier bands on the onset of necking in uniaxial tension of strip cast AA5754 sheets. Scripta Mater. 53, 499-503 (2005).

18. Halim, H., Wilkinson, D. S. \& Niewczas, M. The Portevin-Le Chatelier (PLC) effect and shear band formation in an AA5754 alloy. Acta Mater. 55, 4151-4160 (2007).

19. Picu, R. C. et al. Strain rate sensitivity of the commercial aluminum alloy AA5182-O. Mater. Sci. Eng. A. 390, 334-343 (2005).

20. Yan, C. et al. Effect of electropulsing on deformation behavior, texture and microstructure of 5A02 aluminum alloy during uniaxial tension. Mater. Sci. Eng. A. 638, 69-77 (2015).

21. Hirth, J. P., Lothe, J. \& Mura, T. Theory of Dislocations (2nd ed.). J. Appl. Mech. 50, 476-477 (1983).

22. Blavette, D. et al. Three-dimensional atomic-scale imaging of impurity segregation to line defects. Science, 286, 2317-2319 (1999).

23. Curtin, W. A., Olmsted, D. L. \& Hector, L. G. A predictive mechanism for dynamic strain ageing in aluminium-magnesium alloys. Nature Mater. 5, 875-80 (2006)

24. Cottrell, A. H. \& Bilby, B. A. Dislocation theory of yielding and strain ageing of iron. Proce. Phys. Soci. 62, 49-62 (1949).

25. Yoshinaga, H. \& Morozumi, S. The solute atmosphere round a moving dislocation and its dragging stress. Philo. Mag. 23(186), $1367-1385$ (1971).

26. Halim, H. Wilkinson, D. S. \& Niewczas, M. The Portevin-Le Chatelier (PLC) effect and shear band formation in an AA5754 alloy. Acta Mater. 55, 4151-4160 (2007).

27. Picu, R. C. et al. Strain rate sensitivity of the commercial aluminum alloy AA5182-O. Mater. Sci. Eng. A. 390, 334-343 (2005).

28. Panteli, A. et al. The Effectiveness of surface coatings on preventing interfacial reaction during ultrasonic welding of aluminum to magnesium. Metall. Mater. Trans. A. 44, 5773-5781 (2013).

29. Curtin, W. A., Olmsted, D. L. \& Hector, J. L. G. A predictive mechanism for dynamic strain ageing in aluminium-magnesium alloys. Nature Mater. 5, 875-880 (2006).

30. Mccormick, P. G. A Model for the Portevin-Le Chatelier effect in substitutional alloys. Acta Metall. 20, 351-354 (1972).

31. Rickman, J. M., LeSar, R. \& Srolovitz, D. J. Solute effects on dislocation glide in metals. Acta Mater. 51, 1199-1210 (2003).

32. Sun, I. H. Cyclic stress-strain response and slip mode modification in fatigue of F.C.C. solid solutions. Scripta Mater. 44, 995-1001 (2001).

33. Jong, S. H. \& Sun, I. H. Temperature dependent slip mode modification in $\mathrm{Cu}-\mathrm{Al}$ solid solution alloy single crystals. Mater. Sci. Eng. A. 565, 9-12 (2013)

34. Sun, I. H. \& Laid, C. Mechanisms of slip mode modification in F.C.C. solid solutions. Acta Metall. Mater. 38, 1581-1594 (1990).

35. Sun, I. H. Influence of Dynamic Strain Aging on the Dislocation Substructure in a Uniaxial Tension Test. Mater. Sci. Eng. 79, 1-7 (1986).

36. Wang, Y. et al. Dislocation motion in the presence of diffusing solutes: A computer simulation study. Acta Mater. 48, 2163-2175 (2000).

37. Cottrell, A. H. \& Jaswon, M. A. Distribution of Solute Atoms Round a Slow Dislocation. Proce. of Roy. Soci. A. 199, 104-114 (1949).

38. Yan, M. G. China aviation material manual. Vol. 3 (Shi, C. X. et al.) aluminum magnesium alloys. Beijing. 195-202 (China standard press, 2001).

39. Rickman, J. M., Lesar, R. \& Srolovitz, D. J. Solute effects on dislocation glide in metals. Acta Mater. 51, 1199-1210 (2003).

40. Blavette, D. et al. Three-Dimensional Atomic-Scale Imaging of Impurity Segregation to Line Defects. Science. 286, 2317-2319 (1999).

\section{Acknowledgements}

This work was financially supported by the National Fundamental Research Program of China (Grant no. 2011CB012806). The authors are grateful to the Analytical and Testing Center, Huazhong University of Science and Technology for technical assistance.

\section{Author Contributions}

Z.L., D.W. and Y.O. conducted the experiments. N.L., Z.L. and L.L. designed the work, N.L. and Z.L. analyzed the results and wrote the manuscript.

Additional Information

Competing financial interests: The authors declare no competing financial interests.

How to cite this article: $\mathrm{Li}$, Z. et al. Low temperature deformation behavior of an electromagnetically bulged 5052 aluminum alloy. Sci. Rep. 6, 29973; doi: 10.1038/srep29973 (2016).

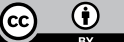
unless indicated otherwise in the credit line; if the material is not included under the Creative Commons license, users will need to obtain permission from the license holder to reproduce the material. To view a copy of this license, visit http://creativecommons.org/licenses/by/4.0/ 